\title{
"DESLOCADOS DA SECA" NA HOSPEDARIA GETÚLIO VARGAS: EXPERIÊNCIAS E TRAJETÓRIAS DE MIGRAÇÃO PARA DIVERSAS PARAGENS (CEARÁ, DÉCADẢ DE 1950)
}

\author{
"DISPLACED FROM THE DROUGHT" AT HOSPEDARIA GETÚLIO \\ VARGAS: MIGRATION EXPERIENCES AND TRAJACTORIES FOR \\ SEVERAL PARAGENS (CEARÀ, 1950S)
}

Renata Felipe Monteiro ${ }^{1}$

RESUMO: A trajetória dos migrantes na Hospedaria Getúlio Vargas (Fortaleza, Ceará) teve início na década de 1940, quando diversos acordos foram concretizados entre Brasil e EUA no contexto da Segunda Guerra Mundial para a extração da borracha na Amazônia. Assim, foram construídos pousos e hospedarias nas regiões Norte e Nordeste, que seriam responsáveis por abrigar e encaminhar os trabalhadores nordestinos para o trabalho na região amazônica. A partir da década de 1950, a Hospedaria Getúlio Vargas tornou-se o principal centro de referência para a população migrante cearense, que almejava ir para outras regiões do país. Baseado em uma variedade de fontes (jornais, entrevistas, dentre outros), objetivamos entender a trajetória de alguns trabalhadores nordestinos que passaram pela Hospedaria Getúlio Vargas na década de 1950.

PALAVRAS-CHAVE: Hospedaria Getúlio Vargas; Trabalhadores; Migração.

ABSTRACT: The trajectory of migrants at the Hospedaria Getúlio Vargas (Fortaleza, Ceará) began in the 1940s, when several agreements were reached between Brazil and the USA in the context of the Second World War for the extraction of rubber in the Amazon. Thus, inns and lodging were built in the North and Northeast regions, which would be responsible for schelter and directing workers from the Northeastern region of Brazil to work in the Amazon region. From the 1950s, the Hospedaria Getúlio Vargas became the main reference center for the migrant population from the state of Ceará, who wanted to go to other regions of the country. Based on a variety of sources

\footnotetext{
* O presente artigo é fruto de reflexões desenvolvidas na minha tese de doutorado em andamento em História Social, na Universidade Federal do Ceará, Fortaleza/CE, intitulada "Deslocados da Seca": o cotidiano dos sertanejos na Hospedaria Getúlio Vargas e a migração para diversas paragens (década de 1950).

${ }_{1}^{1}$ Doutoranda em História Social pela Universidade Federal do Ceará e professora de história da rede municipal de educação de Fortaleza/CE. Email: renataclio@ hotmail.com
} 
(newspapers, interviews, among others), we aim to understand the trajectory of some workers from Northeast region who passed through the Hospedaria Getúlio Vargas in the 1950s.

KEYWORDS: Hospedaria Getúlio Vargas; Workers; Migration.

A construção da Hospedaria Getúlio Vargas ${ }^{2}$ teve início no contexto da Segunda Guerra Mundial, quando diversos acordos entre Brasil e Estados Unidos foram assinados em março de 1942, para a exploração de matérias primas e muitos trabalhadores foram recrutados, sobretudo do Ceará, para a exploração da borracha nos seringais da Amazônia. Através do Serviço Especial de Mobilização dos Trabalhadores para a Amazônia (SEMTA) ${ }^{3}$, em parceria com outras instituições, como, por exemplo, o Serviço Especial de Saúde Pública $(\mathrm{SESP})^{4}$, foi organizado rapidamente todo um sistema que implicava assistência às famílias (pousos e hospedarias ${ }^{5}$ ), seleção dos trabalhadores, alojamento em barracas, exames médicos, alimentação, transporte, vestuário e adiantamentos, até a colocação nos seringais (SECRETO, 2007).

A Hospedaria Getúlio Vargas foi criada nesse contexto, sendo inaugurada no dia em 15 de março de 1943, como "um modelo de organização", tendo o propósito de abrigar provisoriamente um total de 1.200 pessoas. De acordo com o Ministro do Trabalho, Marcondes Filho, os trabalhadores recebiam diariamente três refeições enquanto aguardavam "confiantes o dia do embarque para o extremo norte". Além disso, a hospedaria

\footnotetext{
${ }^{2}$ A Hospedaria Getúlio Vargas, atualmente uma Unidade de Abrigo de Idosos do Governo do Estado do Ceará e subordinada à Secretaria do Trabalho e Desenvolvimento Social (STDS), funcionava na Avenida Olavo Bilac, 1280, bairro São Gerardo-Fortaleza/Ceará.

${ }^{3}$ O SEMTA foi criado em 30 de novembro de 1942, sendo substituído pela Comissão Administrativa de Encaminhamentos de Trabalhadores (CAETA) em 14 de setembro de 1943.

${ }^{4}$ O SESP tinha o objetivo de organizar e superintender as hospedarias administradas pelo Departamento Nacional de Imigração (DNI). Dentre os diversos serviços, podemos citar: proceder exame médico de todos os trabalhadores e pessoas de suas famílias que desejassem ingressar nas hospedarias administradas pelo DNI e proceder exame médico dos trabalhadores alojados nas hospedarias para confecção das listas de embarque, deliberando sobre aqueles que estão ou não em condições de empreender viagem.

${ }^{5}$ As principais hospedarias de migração construídas entre as décadas de 1940 e 1950 foram: Hospedaria Eduardo Ribeiro (Manaus-AM), Hospedaria Tapanã (Belém-PA), Hospedaria Macapá (AP), Hospedaria Copoatá (São Luiz-MA), Hospedaria Getúlio Vargas (Fortaleza-CE) e Hospedaria Corinto (MG).
} 
distribuía redes para todas as pessoas, "proporcionando, deste modo, condições decentes de vida aos trabalhadores" (Jornal O Povo/CE, 16 de março de 1943). A expectativa era que o trabalhador, após ser liberado pelos médicos do SESP, recebesse passagem para migrar juntamente com a família para a região Norte do país. Vale ressaltar, contudo, que a princípio o transporte dos trabalhadores cearenses para a Amazônia era realizado de duas maneiras: aqueles recrutados pelo SEMTA - denominados "soldados da borracha" - faziam seus deslocamentos por terra até São Luiz usando caminhão pau-de-arara e trem. Aqueles que fossem encaminhados pelo Departamento Nacional de Imigração (DNI), órgão responsável pelas hospedarias e pousos pelo país, eram transportados pelos navios do Loyde Brasileiro. Após a extinção do SEMTA transformando-se em CAETA - em setembro de 1943, o DNI retomou o domínio sobre o transporte desses nordestinos.

Os idealizadores da Hospedaria Getúlio Vargas a denominavam de "modelo de organização" que deveria ser seguido pelas outras hospedarias e pousos existentes na década de 1940 nas regiões Norte e Nordeste, sobretudo, a Hospedaria Tapanã, construída em Belém/Pará. Mas apesar do discurso e do projeto inicial - abrigar provisoriamente 1200 pessoas, oferecendo alimentação e relativo conforto -, ao longo da existência da Hospedaria Getúlio Vargas (1943 a 1972), o respectivo recinto de hospedagem tornou-se um centro de conflitos e disputas na cidade de Fortaleza. Assim, nossa proposta na escrita da tese é analisar essas metamorfoses no projeto, tal como discute o antropólogo

\footnotetext{
${ }^{6}$ Os trabalhadores recrutados pelo SEMTA passaram a ser denominados pela propaganda varguista e também se autodeclaravam "soldados da borracha", já que lutavam, tal como seus companheiros soldados na Europa, pela vitória contra os nazistas. Para entender melhor sobre esses sujeitos ver: GOIS, Sarah Campelo Cruz. As linhas tortas da migração: estado e família nos deslocamentos para a Amazônia (1942-1944). 2013. 198 f. Dissertação (Mestrado em História Social) - Centro de Humanidades, Universidade Federal do Ceará, Fortaleza, 2013; GUILLEN, Isabel Cristina Martins. Errantes da selva: histórias da migração nordestina para a Amazônia. 1999. 310 f. Tese (Doutorado em História) - Instituto de Filosofia e Ciências Humanas, Universidade Estadual de Campinas, Campinas, 1999; MORALES, Lúcia Arrais. Vai e vem, vira e volta: as rotas dos soldados da borracha. São Paulo: Annalume; Fortaleza: Secult, 2002 e SECRETO, Maria Verônica. Soldados da borracha: trabalhadores entre o sertão e a Amazônia no Governo Vargas. São Paulo: Editora Fundação Perseu Abramo, 2007.
} 
Gilberto Velho - que analisa a relação entre projeto, campo de possibilidades e metamorfose -; percebendo quais circunstâncias possibilitaram essas mudanças, sobretudo, na década de 1950. E no respectivo artigo, nossa proposta é problematizar sobre as experiências dos migrantes abrigados na respectiva hospedaria, buscando entender ainda quais suas trajetórias de migração para diversas regiões do país durante a década de 1950.

$\mathrm{Na}$ tentativa de fugir das agruras da seca em 1953, o senhor Gabriel Gomes de Lima migrou da localidade de Pedro Velho, no Rio Grande do Norte, juntamente com a esposa Satina e seus seis filhos em direção à cidade de Fortaleza. Mas ao buscarem abrigo na Hospedaria Getúlio Vargas, em março daquele ano, não conseguiram vaga naquele recinto de hospedagem, ficando recolhidos em um terreno baldio defronte à hospedaria embaixo de cajueiros. Passaram um mês nesse espaço, aguardando ansiosamente que alguém migrasse para que eles pudessem ser alistados. O filho mais velho do senhor Gabriel Gomes, Demétrio, diante das dificuldades encontradas na capital cearense "vendia macaxeira para ajudar a sustentar a família" (COUTINHO, 2015: 105). E tal como Demétrio, muitos eram aqueles migrantes que diante das dificuldades enfrentadas na hospedaria percorriam a cidade de Fortaleza, vendendo produtos ou mendigando pelas ruas.

Além desse episódio, os filhos do senhor Gabriel Gomes de Lima José, Maria, Darcy e Demétrio - em entrevista à socióloga Priscila Coutinho relatam outras experiências vivenciadas no período que estiveram em Fortaleza, nas dependências (ou adjacências) da Hospedaria Getúlio Vargas. Um dos momentos mais marcantes para a família Lima foi o show que o cantor Luiz Gonzaga deu para os migrantes nordestinos abrigados naquele recinto. $\mathrm{O}$ show fazia parte de um projeto para arrecadação de donativos à população pobre nordestina, atingida pela seca. Luiz Gonzaga, de acordo com o jornal Diário de Noticias (RJ), após cantar para os abrigados na hospedaria

...disse estar impressionado em haver tomado parte em vários festivais no sul do país, arrecadando milhares de cruzeiros em benefício dos flagelados cearenses e que até o momento não houvessem recebido. Disse, também, que, em face do acontecido faria, de agora por diante, uma campanha contra a 
doação de auxilio aos flagelados. (Jornal Diário de Notícias/RJ, 21 de maio de 1953).

Os irmãos Lima relataram que o cantor Luiz Gonzaga chorou de tristeza ao ver a situação dos trabalhadores abrigados na Hospedaria Getúlio Vargas, denunciando os "[...] tubarões que haviam roubado o dinheiro que ele mandou para ajudar os aflagelados da hospedaria" (COUTINHO, 2015:107). Percebe-se assim, a partir da reportagem e da fala dos filhos do senhor Gabriel Gomes, que o cantor Luiz Gonzaga protestava contra o desvio das verbas que, teoricamente, foram arrecadadas em vários eventos, mas que não chegaram até os nordestinos abrigados na hospedaria. Uma denúncia semelhante foi realizada pela Revista Movimento, ao relatar que o dinheiro arrecadado pela campanha "Ajuda teu irmão"7, segundo um funcionário da hospedaria, não chegou às dependências do respectivo recinto: "dessa campanha não chegou aqui nem mesmo uma camisa sem mangas" (Revista Movimento/RJ, abril de 1954).

Além disso, o senhor Gabriel Gomes de Lima e sua família vivenciaram momentos angustiantes durante o período que estiveram ao relento, nos cajueiros próximos à hospedaria, como relata José Ramos de Lima:

Toda vez que dava $20 \mathrm{~h}$ vinha chuva. A nossa barraca ficava embaixo de um cajueiro no Alagadiço, aí todo dia vinha inverno, né. Aí o pai disse que ia invadir a igreja, né. Aí três pais de família disse: Seu Gabriel, corta o baralho pra mim? Quer dizer, pra entrar no meio, né? Aí foi os três pais de família na frente e as mulheres atrás com a meninada. Veio aquela fila. Aí o vigia veio, começou a se zangar e meu pai disse: 'Olha, pelo amor de Deus, você fique quieto aí, senão você vai pro Americano'. O Americano era um vagão que tinha. Aí ele disse que ia ligar pras Forças [armadas]. Quando as Forças chegaram, aí eles deram comida, remédio, aí chegou com tudo. Aí fomos apoiados pelas forças (LIMA, 2015:107).

A respectiva igreja - atualmente Igreja São Judas Tadeu - teve seus alicerces iniciados na década de 1940, quando o Delegado Regional do Ceará Raul Uchoa cedeu uma parte do terreno da hospedaria para a construção do templo, mas somente no final da década de 1950 foi concluída. E nesse período

\footnotetext{
${ }^{7}$ Campanha realizada nos estados do Sudeste em 1953, com o apoio de inúmeros artistas, dentre eles o compositor Humberto Teixeira, que tinha o proposito de arrecadar donativos para a população nordestina que sofria mais uma vez as agruras da seca.
} 
serviu como pouso para inúmeros migrantes, deixados ao relento devido às dificuldades de conseguir vagas na Hospedaria Getúlio Vargas. Além disso, percebe-se pela fala do senhor José Ramos como a ação do Exército, diante dos problemas vivenciados - ausência de abrigo, fome, doenças - foi algo marcante na memória deste (em 1953 tinha apenas 05 anos). Essa valorização das ações das Forças Armadas devia-se, possivelmente, a doação das barracas que protegeriam os retirantes (sol e chuva) e dos utensílios para a cozinha improvisada que montaram no terreno baldio. Além disso, Ramos relata que o Exército realizou outras ações, como o corte de cabelo e a extração de dentes das pessoas.

Quanto tempo o senhor Gabriel Gomes de Lima e sua família ficaram desabrigados, vivendo nas barracas improvisadas pelo Exército? Conseguiram se alistar nas dependências da hospedaria? De acordo com Ramos, a família conseguiu posteriormente obter passagens para viajar para a região Norte, no navio Poconé (companhia Loyde Brasileiro). Concluímos, dessa forma, que a família Lima conseguiu ser alistada como migrante na Hospedaria Getúlio Vargas, ficando abrigada até meados ${ }^{8}$ de 1953 naquele recinto. Passaram oito dias navegando em direção à Hospedaria Tapanã, em Belém/Pará, recebendo Gabriel Gomes diversas propostas de emprego ao desembarcar naquele recinto de hospedagem, como relata Ramos:

Aí todo dia chegava muita gente atrás de papai [na Hospedaria Tupanã] pra trabalhar na vacaria, mas ele não queria. Já que tava lá, queria um negócio melhor, né. Aí chegou um senhor com nome de Zé Guedes e ajeitou com ele pra ir pra fazenda dele. Aí ele foi, ajeitou e marcou o dia na quarta-feira que ele vinha, que ele era proprietário do caminhão naquela época e vinha apanhar a gente. Foi chegar era 6 horas da noite, aí nós viemos e fomos chegar era 12 horas na fazenda. Aí ele ficou lá um ano, mas com um ano ele não queria mais ser sujeito, sabe? Ele queria crescer. Aí falou com o homem que queria botar três hectares de terra, mas só se fosse de mata virgem... aí ele exigiu isso porque ele sabia que o homem não tinha essa terra lá, sabe? Num tinha como arrumar, né. Era pra ele poder sair fora, né. Aí

\footnotetext{
${ }^{8}$ Chegamos à conclusão que a família de Gabriel Gomes de Lima permaneceu até o mês de maio de 1953 nas dependências da Hospedaria Getúlio Vargas, já que a família presenciou o show de Luiz Gonzaga em maio de 1953, em prol dos flagelados.
} 
disse: 'Dom João que tem esses terreno todo, mas ele é muito bravo'. Só que ele falava alto por ele mesmo, sabe? Não tinha nada disso não, não era bravo não. Aí ele foi lá com Dom João e levou um outro ano, mas lá ele já montou comércio, começou a subir, né. Aí no fim do ano ele colheu 360 sacos de arroz... eu lembro ainda. Colheu muito arroz e depois comprou a terrinha dele. (LIMA, 2015:110)

Gabriel Gomes de Lima, diferentemente da maioria dos nordestinos que migravam para outros lugares, era alfabetizado e tinha bastante experiência na administração de propriedades rurais, já que havia possuído uma pequena propriedade no interior nordestino. Assim, recusou algumas propostas de emprego que considerou inadequadas, preferindo aguardar nas dependências da hospedaria. Isso o diferenciava também dos outros migrantes, pois a regra consistia em aceitar qualquer ocupação. Lima, após permanecer meses trabalhando na fazenda de José Guedes, estabeleceu-se em um lugar denominado Guamá (Pará), que naquele período desenvolvia um projeto do Governo Federal de colonização da terra, recebendo migrantes de vários lugares do Brasil e de imigrantes, sobretudo do Japão, para o desenvolvimento de várias culturas, destacando-se o arroz e a pimenta. Vale ressaltar que, apesar de Gabriel Lima ter conseguido se adaptar à região e conseguir desenvolver vários projetos na agricultura, retornou na década de 1960 ao interior do Nordeste, já que sua esposa Satina não teve o mesmo êxito nessa adaptação.

Os abrigados na Hospedaria Getúlio Vargas, assim como Gabriel Lima, preferiam - caso houvesse a oportunidade de escolha - a região Norte para migrar, possivelmente porque havia uma longa tradição na migração entre o Ceará e a região amazônica desde o século $\mathrm{XIX}^{9}$, sobretudo, nos períodos de

\footnotetext{
${ }^{9}$ Para entender melhor esse fluxo migratório para a região Norte, a partir de meados do século XIX e, sobretudo, partir da seca de 1877-79, ver: CARDOSO, Antônio Alexandre Isidio. Nem sina, nem acaso: a tessitura das migrações entre a Província do Ceará e o território amazônico (1847-1877). 2011. 244 f. Dissertação (Mestrado em História Social) - Centro de Humanidades, Universidade Federal do Ceará, Fortaleza, 2011; LACERDA, Franciane Gama. Migrantes cearenses no Pará: faces da sobrevivência (1889-1906). 2006. 346 f. Tese (Doutorado em História Social) - Faculdade de Filosofia, Letras e Ciências Humanas, Universidade de São Paulo, São Paulo, 2006; NETO, Edgar Braga. Emigração Cearense entre 1888 e 1915: sentidos, controle e configuração social dos migrantes. 2012. 172 f. Dissertação (Mestrado em Sociologia) - Centro de Humanidades, Universidade Federal do Ceará, Fortaleza, 2012, e BARBOZA, Edson Holanda Lima. A hidra cearense: rotas de retirantes e escravizados entre o Ceará e as fronteiras do Norte (1877-1884). 2013. 255 f. Tese (Doutorado em História
} 
seca. Essa migração, contudo, não ocorria somente nos períodos de estiagem, mas sobressaia-se quando havia as instabilidades climáticas. Mas o que fazer quando uma grande leva de trabalhadores abandonavam suas ocupações, nas propriedades rurais, para migrarem para outras paragens? Um das grandes preocupações dos governantes, políticos, fazendeiros, jornalistas e religiosos era o êxodo rural, que poderia desabastecer o Nordeste dessa mão-de-obra barata e abundante, esvaziando o campo. Dessa forma, houve um intenso debate em torno dessa problemática na década de 1950.

Em 1956, como salienta a historiadora Lara de Castro Ferreira, a Igreja Católica estava preocupada com os trabalhadores do campo dispersando-se com a migração para outras regiões, principalmente nos períodos de seca. E essa preocupação foi colocada no I Encontro de Bispos do Nordeste, realizado na cidade de Campina Grande (PB), entre os dias 21 e 26 de maio de 1956, discutindo-se "não somente o amparo aos 'retirantes', 'pobres de cristo', mas também a influência que comunistas e outros ativistas políticos pudessem exercer sobre a população de migrantes" (FERREIRA, 2016: 35-36). A solução apontada nesse congresso para evitar o êxodo foi investir em políticas públicas desenvolvimentistas, com construções espalhadas pelo interior do país. A ideia era ocupar os espaços vazios no Brasil - ideia em voga desde o governo de Getúlio Vargas - e os trabalhadores em obras públicas, evitando que estes migrassem para os grandes centros urbanos do país. Vale ressaltar, porém, que a quantidade de vagas oferecidas nessas obras públicas não era suficiente para absorver todos os trabalhadores desempregados, ficando muitos na expectativa de serem alistados pelo governo. Havia ainda aqueles que mesmo empregados, não conseguiam alimentar seus familiares com o salário recebido ou com a alimentação distribuída. Possivelmente a baixa remuneração nas propriedades rurais, assim como nas obras governamentais, funcionasse como uma estratégia para segurar esses trabalhadores no campo, prendendo-os a atividades extenuantes e degradantes, ditadas pelos donos da terra.

Social) - Faculdade de História, Pontifícia Universidade Católica de São Paulo, São Paulo, 2013. 
A migração surgia como a última alternativa na busca por melhores condições de vida, como, por exemplo, para o agricultor Manoel Antônio, morador da cidade de Acaraú no interior do Ceará. Este trabalhava na agricultura para manter a esposa e os seis filhos, mas durante a seca de 1958 viu-se sem a possibilidade de obter produtos da terra. Diferente dos companheiros, não se alistou imediatamente nas obras que o governo oferecia na região Norte do Estado do Ceará, preferindo vender lenhas para obter o sustento, pois ainda tinha esperança que houvesse chuvas até o dia de São José $^{10}, 19$ de março. Mas suas esperanças foram desfeitas quando não houve chuva nesse dia. Assim, após a escassez das lenhas para o sustento da família, restou o alistamento na obra do Riachão. Naquela obra sofria com os desmandos do fornecedor, que lhe dava o que queria, ganhando muito pouco pelo trabalho. Aos sábados retornava nos vagões dos trens da Rede de Viação Cearense (RVC) para sua residência, levando comida para a família. Mas "a comida era ruim. O milho era só o pó. O feijão era duro, velho e preto" (Jornal O Estado/CE, 23 de agosto de 1958).

E diante dessas dificuldades - problemas com o fornecedor, pouco dinheiro, comida ruim - ficou fascinado com a fala de um conhecido, Florêncio, que conversava em uma "bodega" próxima a Praça da Igreja Católica de Acaraú. Florêncio relatava as aventuras vivenciadas como "soldado da borracha" na década de 1940 e das maravilhas da Amazônia (abundância das chuvas, dos rios, dos peixes, das matas com caças, as árvores com frutos e da fartura).

Manoel voltou para casa pensando nas palavras de Florêncio e na fartura da Amazônia. E no caminho para casa tomou a decisão de ir para a Amazonas, levando tudo e todos. Pela manhã informou a mulher Purificação da sua decisão. Ela que estava sofrendo com a fome, não via melhor solução que não fosse fugir dali, fugir da fome. Na segunda, no trem que levava os cassacos para a obra do governo não estava Manoel. Iria empreender uma viagem muito mais longa. Gastou o dia arrumando os pertences, liquidando os

\footnotetext{
${ }^{10}$ São José é o padroeiro do Estado do Ceará e de acordo com a tradição popular e a crença religiosa, caso não chova até ou no dia de São José, dia 19 de março, teremos um período de seca.
} 
pertences e arranjando um dinheirinho. Depois foram rumo à Sobral. De Sobral vieram em um vagão de segunda classe para Fortaleza. Vieram parar no Otávio Bonfim e de lá, quase tateando, foram em direção à Hospedaria Getúlio Vargas (Jornal O Estado/CE, 23 de agosto de 1958).

Assim, influenciado pelas palavras de Florêncio, Manoel resolveu abandonar tudo e empreender uma longa viagem em direção ao Norte do país, em busca de melhorias para ele e sua família. Em que medida, contudo, Florêncio vivenciou todas essas benesses na Amazônia, enquanto trabalhava como "soldado da borracha”, que foram narradas para Manoel? Essa problemática é pertinente, já que nos documentos oficiais consta que dos milhares de brasileiros (homens e mulheres) que migraram em direção à Amazônia para trabalhar na extração do látex, entre 1942 e 1945, 45 mil morreram. Daqueles que sobreviveram às doenças e ao trabalho exaustivo, muitos não conseguiram passagem para retornar às suas localidades de origem. Essa discussão nos direciona ao sociólogo argelino Abdelmalek Sayad que, ao analisar sobre a situação dos jovens em uma pequena aldeia na Cabília (Argélia) que migravam para a França no período posterior à Segunda Guerra, percebeu que aqueles que retornavam para a respectiva aldeia construíam uma versão diferente de suas condições de vida, sem problemas, apenas benesses. De acordo com um emigrante de Cabília, entrevistado por Sayad, antes de emigrar acreditava que na França seria como na aldeia, pois iria se encontrar com seus parentes e usufruir de todas as maravilhas descritas na aldeia por aqueles que migraram antes dele. Mas o que descobriu foi que era preciso chegar à França para descobrir a verdade. Somente naquele lugar os sujeitos, seus conterrâneos de Cabília, contavam concretamente sobre suas péssimas condições de vida. (SAYAD, 1998)

Será que, tal como os jovens da aldeia de Cabília, Florêncio criou outra versão para sua experiência como "soldado da borracha" na Amazônia e contou apenas essa versão para Manoel? Este percebeu, quase imediatamente à sua chegada em Fortaleza, que sua jornada em direção às maravilhas da região amazônica teria muitos reveses. A primeira dificuldade encontrada foi na Hospedaria Getúlio Vargas, que estava superlotada. Os registros de movimento 
de entrada da respectiva hospedaria, entre os meses de janeiro e junho de 1958 - período que possivelmente Manoel e sua família esteve na hospedaria -, comprovam essa afirmativa: 23.300 pessoas foram registradas, dos quais 10.218 viajaram, 1.344 desistiram de migrar, 517 morreram e 11.177 ainda aguardavam embarque (ARAÚJO, 2000:85). Assim, um recinto de hospedagem que teria a capacidade máxima para 1.200 pessoas, estava em junho de 1958 com mais de 11 mil pessoas aguardando embarque para migrar. E com essa grande quantidade de pessoas, os problemas aumentavam sobremaneira: fome, doenças, mortes e ausência de condições sanitárias.

Após sofrer "todas as humilhações possíveis" na Hospedaria Getúlio Vargas, Manoel um dia foi levado ao porto do Mucuripe, sendo "sacudido dentro de um navio, com sua parca economia, pertences e sua família”. Mas a esperança de ver "a fartura da Amazônia" o fez aguentar todas as atribulações existentes na respectiva hospedaria (Jornal O Estado/CE, 23 de agosto de 1958). Ao chegar, contudo, à Hospedaria de Tapanã em Belém, foi tão maltratado quanto nas obras do governo em Acaraú ou na Hospedaria Getúlio Vargas em Fortaleza. Sofrimento que se agravou com a espera, durante dias, por colocação de trabalho na região amazônica. Um dia, porém, outro cearense "curtido e endurecido pelo trabalho no seringal" contratou alguns trabalhadores alojados na Hospedaria Tapanã para trabalhar no seu seringal no baixo Juruá, dentre eles Manoel. "Lá se foi Manoel e sua família. Outros dias de sofrimento no gaiola ${ }^{11}$. Os meninos adoeceram e os dois mais novos morreram durante a viagem" (Jornal O Estado/CE, 23 de agosto de 1958). Estabelecido no seringal, Manoel escrevia cartas para seus familiares no interior do Ceará, relatando sobre os infortúnios da viagem para o Norte e sobre outras amarguras do cotidiano na floresta amazônica.

Manoel, após passar por vários seringais, conseguiu estabelecer-se em um seringal no rio Purus (Amazônia). Soube que um deputado estadual, conterrâneo de Acaraú - havia votado nele -, José Colombo de Sousa tinha

\footnotetext{
${ }^{11}$ Gaiola é um tipo de embarcação usada nos rios brasileiros, sendo bastante comum nos rios da Amazônia, onde as pessoas normalmente colocam redes para dormir.
} 
proposto uma lei que distribuía "um pedaço de terra para os retirantes na beira do rio Amazonas e mandava o governo manter os pobres quando lá chegassem" (Jornal O Estado/CE, 23 de agosto de 1958). Possuir um pedaço de terra era a grande benesse que Manoel aguardava, desde o domingo que ficou encantado com as histórias de Florêncio sobre a floresta amazônica. Não seria mais obrigado a suportar fornecedores trapaceiros, trabalhos extenuantes em obras emergenciais do governo e parcos salários nas propriedades de outros. Nas cartas enviadas aos familiares dizia que por lá ficaria, "esperando que o governo fizesse com ele e seus companheiros o que fazia com os japoneses quando chegavam lá, todos eram bem tratados e com documentos de posse da terra" (Jornal O Estado/CE, 23 de agosto de 1958).

As terras cultivadas por Gabriel de Lima, na região de Guamá, e por Manoel Antônio no Purus faziam parte de um projeto de recolonização do Governo Federal - iniciado por Getúlio Vargas e continuado por Juscelino Kubitschek - de algumas áreas do país, no qual os migrantes nacionais e internacionais (os japoneses) construíam suas casas e desenvolviam diversas culturas nas propriedades do governo. Os principais núcleos coloniais foram estabelecidos no norte do Brasil, mas havia alguns no Nordeste, como, por exemplo, no Ceará. A migração dessa população nordestina, porém, como citado anteriormente, não era incentivada constantemente e em alguns momentos houve tentativas de coibir ou diminuir o fluxo de pessoas para outras regiões. O deputado estadual (São Paulo) Paulo Abreu em 1952 organizou um projeto de lei, $\mathrm{n}^{\circ} 1710 / 52$, que tentava regulamentar o êxodo das populações do Norte e Nordeste para a região do Sudeste, ou melhor, para São Paulo. O deslocamento dessas pessoas para a capital paulista, de acordo com o documento, seria regulamentado por postos de fiscalização em diversas localidades. O projeto, apesar de bem aceito em São Paulo, não foi aprovado.

Durante a seca de 1951-1953 houve outras tentativas de coibir a saída dos nordestinos para diversas regiões do país, como salienta a historiadora Lara de Castro Ferreira, já que o jornal "o Correio da Manhã do Rio de Janeiro informava que Getúlio Vargas já havia aprovado medidas de impedimento da 
saída de nordestinos dos seus lugares de origem" (FERREIRA, 2016:38). A ideia desses governantes, políticos e religiosos era cercear e regulamentar o deslocamento desses sujeitos pelo país, determinando quando e para onde poderiam migrar. Como salienta o historiador Paulo Fontes,

os anos 50 foram, provavelmente, o momento no qual o
impacto da migração interna foi mais acentuado. Pela
primeira vez na cidade de São Paulo o número de migrantes
de outras regiões ultrapassava o das pessoas vindas do
interior do estado. (...) Os trabalhadores oriundos dos estados
nordestinos compunham a grande maioria dos recém
chegados e empregavam-se em massa nos variados ramos da
indústria e serviços em franca expansão na região
metropolitana (FONTES, 2002: 54-55).

Os nordestinos que migravam em direção a São Paulo na década de 1950, vindos de diversos estados do Nordeste - a maioria, contudo, era proveniente do Estado da Bahia -, utilizavam como transporte os caminhões pau-de-arara, passando dias nas estradas até chegar à capital paulista ou à região metropolitana em busca de ocupação na indústria e outros setores produtivos. Mas esse aumento do fluxo de migrantes na década de 1950 para São Paulo poderia ser justificado somente pelas estiagens? Essa justificativa esvazia-se quando percebemos que durante toda essa década os nordestinos e, sobretudo, os cearenses recorriam à Hospedaria Getúlio Vargas em busca de passagem para migrar, mesmo quando havia estabilidade climática. Busca por melhores condições de vida, com salários dignos, acesso a direitos trabalhistas e/ou a posse de uma propriedade rural, possivelmente é a resposta mais plausível para esse deslocamento constante. Como salienta a socióloga Neyara Araújo, a partir da década de 1950 na cidade de Fortaleza, esses sujeitos, denominados anteriormente simplesmente como "retirantes" e/ou "flagelados", passaram a ser percebidos como "deslocados da seca", já que

corriam para a cidade porque tinham ouvido falar pelo rádio que aqui havia recursos, des-locados em busca de se alocarem. Onde? Houvera muitas placas, sim, nas fachadas das industrias novas, nas obras da construção civil, solicitando: Precisa-se de. E vinham chegando às carradas. Diz que os próprios prefeitos do interior, acossados pela vaga, alugavam caminhões e mandavam soltar aqui. A Hospedaria Getúlio Vargas sofreu horrores nessa época. O 
Sr. Expedito (...) contou que não tinham mais como acomodar o número excessivo, que era um verdadeiro exagero. Em novembro de 1958, esse número ultrapassou os onze mil (ARAÚJO, 2000:83).

Em direção à Hospedaria Getúlio Vargas direcionaram-se milhares de "deslocados da seca" em 1958, causando temor nas autoridades governamentais e em outros sujeitos. O que seria possível fazer para resolver esse problema? A migração, apesar de ser questionada e evitada em diversos momentos, foi a solução encontrada para resolver o problema da superlotação nas dependências da hospedaria. O grande temor era a repetição de cenas de revolta registradas pela imprensa em maio de 1958, quando o administrador da hospedaria Waldemar Nepomuceno foi ameaçado e expulso do recinto de hospedagem pelos migrantes e a cozinha e outros equipamentos foram destruídos durante o motim. Assim, em dezembro de 1958 foi organizada pelo Instituto Nacional de Imigração e Colonização ${ }^{12}$ (INIC) uma força tarefa, denominada "Operação Flagelados", contando com o apoio da Marinha, Aeronáutica e Exército, tendo como objetivo fazer o deslocamento, em curto prazo, de 12 mil migrantes abrigados na Hospedaria Getúlio Vargas.

Aníbal Teixeira, diretor do INIC, argumentava que essa operação iniciara-se no dia 05 de dezembro, quando o navio Almirante Alexandrino transportou 600 migrantes para a hospedaria existente na ilha de Flores (Rio de Janeiro), que seriam destinados aos cafezais no Paraná e para a região de Goiás. Outros haviam sido enviados para Brasília e Anápolis (360), mas 80\%, ou seja, 10 mil "desejava ir para a Amazônia". Na região norte, muitos seriam alocados nos núcleos de colonização existente em Santarém e outras localidades próximas, desenvolvendo o plantio "em suas próprias terras, de malva, pimenta do reino, arroz, milho e outros cereais" (Jornal Diário de Notícias/RJ, 20 de dezembro de 1958).

Os jornais oposicionistas relatavam que essa "Operação Flagelados" visava somente escoar essa população pobre migrante para outras paragens, não

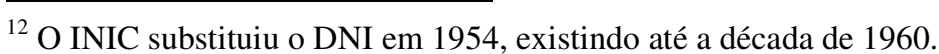


havendo a preocupação de como seriam recepcionados nas outras hospedarias dirigidas pelo INIC ou onde os mesmos seriam empregados:

\begin{abstract}
noticias procedentes de Santarém e de Manaus, trazidas por pessoas chegadas recentemente a Fortaleza, dizem que numerosas famílias de emigrantes já andam pelas ruas das cidades, pedindo esmola. Isto significa que a única preocupação dos promotores da "operação flagelados" consiste apenas em organizar a retirada em massa, não havendo, porém, recepção e encaminhamento nos locais de destino (Jornal Voz Operária/RJ, 17 de janeiro de 1959).
\end{abstract}

Vale ressaltar que, posteriormente à seca de 1958, os discursos sobre a regulamentação das migrações internas voltaram à pauta de discussão de governantes, políticos e religiosos. No II Encontro de Bispos do Nordeste, realizado em Natal (RN) em maio de 1959, estabeleceu-se, dentre diversas propostas, que as hospedarias de migrantes de Fortaleza, Belém e Manaus deveriam ser transformadas em hospedarias de zona rural, sendo constituído um grupo de trabalho para executar essa proposta. A ideia, apesar de não ter sido concretizada, nos possibilita problematizar que após essa grande estiagem da década de 1950, a preocupação com o deslocamento constante dessa população pobre migrante assustava sobremaneira os habitantes dos grandes centros urbanos do país, sendo necessário afastá-los de qualquer maneira para o campo e impedi-los de migrar quando houvesse outra instabilidade climática.

\title{
Considerações finais
}

Assim, ao analisarmos essa variedade de documentos (jornais, documentos oficiais, revistas, entrevistas, dentre outros) sobre as experiências e trajetórias dos migrantes na Hospedaria Getúlio Vargas em Fortaleza, sobretudo na década de 1950, esperamos contribuir para um aprofundamento das discussões que envolvem esses sujeitos, que em busca de obter melhores condições de vida, assim como para fugir de um sistema de trabalho opressor nas propriedades fundiárias de outros ou nas obras governamentais, enfrentavam dificuldades nas dependências ou adjacências daquela hospedaria (fome, doenças, ausência de condições sanitárias, etc.), os perigos da viagem 
até as regiões Norte, Sudeste, Centro-Oeste e Sul, e o futuro incerto em outras paragens.

\section{Referências}

AGUIAR, Sidney Barata de. Arigós, jabá e o caso da carne verde: vivências populares na cidade de Manaus (1939-1949). 2012. 115 f. Dissertação (Mestrado em História Social) - Instituto de Ciências Humanas e Letras, Universidade Federal do Amazonas, Manaus, 2012.

ARAÚJO, Maria Neyara de Oliveira. A miséria e os dias: história social da mendicância no Ceará. São Paulo: Hucitec, 2000.

BARBOZA, Edson Holanda Lima. A hidra cearense: rotas de retirantes e escravizados entre o Ceará e as fronteiras do Norte (1877-1884). 2013. 255 f. Tese (Doutorado em História Social) - Faculdade de História, Pontifícia Universidade Católica de São Paulo, São Paulo, 2013.

BASTOS, Nilo Chaves de Brito. SESP/FSESP: 1942 - Evolução Histórica 1991/- 2º ed. Brasília: Fundação Nacional de Saúde, 1996.

CARDOSO, Antônio Alexandre Isidio. Nem sina, nem acaso: a tessitura das migrações entre a Província do Ceará e o território amazônico (1847-1877). 2011. 244 f. Dissertação (Mestrado em História Social) - Centro de Humanidades, Universidade Federal do Ceará, Fortaleza, 2011.

CEARÁ. As migrações para Fortaleza. Fortaleza: Secretaria de Administração/Imprensa Oficial, 1967.

COUTINHO, Priscila de Oliveira. "Meu sonho era maior que eu": Biografia sociológica de uma trânsfuga de classe. 2015. 300 f. Tese (Doutorado em Sociologia) - Centro de Ciências Sociais, Universidade Federal do Rio de Janeiro, Rio de Janeiro, 2015.

FERREIRA, Lara Vanessa de Castro. Cassacos. Trabalhadores na Lida Contra a Fome e a Degradação nas Obras Públicas em Tempos de Seca (Ceará - Anos 1950). 2016. 240 f. Tese (Doutorado em História Social) - Faculdade de Filosofia e Ciências Humanas, Universidade Federal da Bahia, Salvador, 2016.

FONTES, Paulo Roberto Guerra. Comunidade operária, migração nordestina e lutas sociais: São Miguel Paulista (1945-1966). 2002. 399 f. Tese (Doutorado em História) - Instituto de Filosofia e Ciências Humanas, Universidade Estadual de Campinas, Campinas, 2002. 
GOIS, Sarah Campelo Cruz. As linhas tortas da migração: estado e família nos deslocamentos para a Amazônia (1942-1944). 2013. 198 f. Dissertação (Mestrado em História Social) - Centro de Humanidades, Universidade Federal do Ceará, Fortaleza, 2013.

GUILLEN, Isabel Cristina Martins. Errantes da selva: histórias da migração nordestina para a Amazônia. 1999. 310 f. Tese (Doutorado em História) Instituto de Filosofia e Ciências Humanas, Universidade Estadual de Campinas, Campinas, 1999.

JUCÁ, Gisafran Nazareno Mota. Verso e reverso do perfil urbano de Fortaleza (1945-1960). São Paulo: Annablume, 2003.

LACERDA, Franciane Gama. Migrantes cearenses no Pará: faces da sobrevivência (1889-1906). 2006. 346 f. Tese (Doutorado em História Social) Faculdade de Filosofia, Letras e Ciências Humanas, Universidade de São Paulo, São Paulo, 2006.

LIMA, José Ramos. Entrevista cedida à COUTINHO, Priscila de Oliveira. "Meu sonho era maior que eu": Biografia sociológica de uma trânsfuga de classe. 2015. 300 f. Tese (Doutorado em Sociologia) - Centro de Ciências Sociais, Universidade Federal do Rio de Janeiro, Rio de Janeiro, 2015.

MENEZES, Marilda Aparecida. Redes e enredos nas trilhas dos migrantes: um estudo de famílias de camponeses-migrantes. Rio de Janeiro: Relume Dumará; João Pessoa, PB: EDUFPB, 2002.

MORALES, Lúcia Arrais. Vai e vem, vira e volta: as rotas dos soldados da borracha. São Paulo: Annalume; Fortaleza: Secult, 2002.

NETO, Edgar Braga. Emigração Cearense entre 1888 e 1915: sentidos, controle e configuração social dos migrantes. 2012. 172 f. Dissertação (Mestrado em Sociologia) - Centro de Humanidades, Universidade Federal do Ceará, Fortaleza, 2012.

NEVES, Frederico de Castro. A multidão e a história: saques e outras ações de massas no Ceará. Rio de Janeiro: Relume Dumará. Fortaleza. CE: Secretaria de Cultura e Desporto, 2000.

NEVES, Frederico de Castro. Getúlio e a Seca: politicas emergenciais na era Vargas. Revista Brasileira de História, São Paulo, v.21, nº40, p.107-131, 2001.

PAIVA, Odair da Cruz; MOURA, Soraya. Hospedaria de imigrantes de São Paulo. São Paulo: Paz e Terra, 2008. 
PORTELLI, Alessandro. Tentando aprender um pouquinho: algumas reflexões sobre a ética na história oral. Projeto História, São Paulo (15), abril de 1997.

ROCHA, Dom Jaime Vieira. Anais - Sob os signos da Esperança e da responsabilidade social - anais do I e II Encontros dos Bispos do Nordeste (Campina Grande, 1956/Natal, 1959). Rio de Janeiro, Presidência da República - Serviço de Documentação, 1960; Campina Grande/PB, EDUEPB, 2016.

SAYAD, Abdelmalek. A Imigração: ou os paradoxos da alteridade. São Paulo: EdUSP, 1998.

SECRETO, Maria Verônica. A ocupação dos "espaços vazios" no governo Vargas: "Discurso do rio Amazonas" à saga dos soldados da borracha. Estudos Históricos, n. 40, p. 115-135, 2007.

SECRETO, Maria Verônica. Soldados da borracha: trabalhadores entre o sertão e a Amazônia no Governo Vargas. São Paulo: Editora Fundação Perseu Abramo, 2007.

SCOTT, James C. Formas Cotidianas da Resistência Camponesa. Tradução: Marilda A. Menezes e Lemuel Guerra. Raízes, Campina Grande, volume 21, $\mathrm{n}^{\circ} 01, \mathrm{p} .10-31$, jan./jun.2002.

THOMPSON, E.P. Costumes em Comum. São Paulo: Companhia das Letras, 1998.

VELHO, Gilberto. Projeto e metamorfose: antropologia das sociedades complexas. Rio de Janeiro: Jorge Zahar Ed, $3^{\text {a }}$ edição, 2003.

Recebido em: 31 de maio de 2020

Aceito em: 05 de julho de 2020 